Article

\title{
Uncertainty Assessment for Determining the Discharge Coefficient $C$ for a Multi-Opening Orifice
}

\author{
Andrzej Mrowiec \\ Faculty of Technology, The President Stanisław Wojciechowski Academy in Kalisz, Poznańska 201-205, \\ 62-800 Kalisz, Poland; a.mrowiec@akademiakaliska.edu.pl; Tel.: +48-62-76-79-544
}

Received: 31 October 2020; Accepted: 26 November 2020; Published: 28 November 2020

\begin{abstract}
This article contains the results of experimental studies of a multi-opening orifice with substitute constriction factor of $\beta=0.5(m=0.25)$, mounted in a DN50 hydraulic measuring flume. Flow measurements were taken from a progressing turbulent flow within Reynolds numbers $(R e=4700-19,500)$. Based on conducted experimental data, flow characteristics, and discharge coefficient $C$ characteristics were determined. Relative expanded uncertainty of determining a discharge coefficient $C$ was estimated within the changes of volume flow $q_{v}$ from 0.35 to $0.68 \mathrm{dm}^{3} / \mathrm{s}$, based on rules from the GUM international standard. The value, determined from uncertainty analysis, did not exceed $1.25 \%$ within the changes of Reynolds numbers $9800 \leq \operatorname{Re} \leq 19,500$.
\end{abstract}

Keywords: volume flow; multi-opening orifice; experimental studies; measurement uncertainty analysis

\section{Introduction}

Fluid mechanics face problems with the measurement of volume flow on a micro-scale, which include, among others, biological systems, especially blood flow measurement [1], and on a macro-scale, in industrial flows. Several different flow meters are used for measuring, mainly for the purpose of controlling the technological process where constant measurement of fluid flow is required. The most common, cheapest, and most reliable devices to do the job are wedge meters. They utilize a sudden constriction of the pipeline which the fluid comes across. Fluid speed rapidly rises, passing through the constriction, which results in a difference in static pressure before and behind the constricting segment. The following devices are normally used as flow build-up constriction devices: Venturi tubes, nozzles, and measuring orifices [2-4]. Orifices are popular for measurement, despite their weaknesses, which include permanent loss of pressure with fluid flow and low rangeability (4:1). Among commonly known measuring orifices, the standard (centrical) orifice, characterized by accuracy at $1.5-2 \%$, was accepted as a basic model $[5,6]$. Many researchers around the globe are looking for new solutions for metering orifices to measure fluid flow, which would be characterized by a constant value of discharge coefficient $C$ in a wide range of changes in Reynolds numbers [7,8]. Such a solution seems to come in the form of a flow meter with a flow choking element-a multi-opening orifice. It features more than one opening, usually cylindrical, in the orifice acting as the flow choking element. The conducted experimental study for such multi-opening orifices of various designs, compared to the standard orifice, allowed easier observation due to lesser distortion of the stream behind the orifice $[9,10]$. This results in a more stable distribution of velocity field, which in turn causes a lesser decrease in build-up pressure at the orifice. Such a design gives the orifice higher ability to counteract the distortions, compared to the standard orifice (as it requires smaller straight segments of the pipeline before and behind the orifice). Such an advantage has been used when building a cut-off ball valve, where the valve ball has a multi-opening orifice built into it for measuring the stream of the flowing liquid [11]. In the literature concerning multi-opening orifices of such type, one can also come across 
a comparison of results from the experiment and numerical modelling for a progressed turbulent flow $[12,13]$. The literature on this topic normally presents results of numerical simulation studies of such orifices, with a different number of holes and different position in the flow plane [14-16]. When estimating uncertainty based on numerical simulations, we often come across very complex models and resulting complications with determining uncertainty sources $[17,18]$. That is why it is much easier and simpler to estimate the uncertainty of measurement by using experimental studies with assumed flow conditions. With the traditional approach to calculating uncertainty, we use the rules from GUM international standard [19], where uncertainty is defined as a parameter of distribution of measurement error probability. With such an approach to the problem of uncertainty assessment, two types of standard uncertainties are determined: type A and type B [20]. To assess type A standard uncertainty, statistical analysis is taken from a series of observations conducted in the same measuring conditions. It is estimated as the experimental standard deviation of mean resulting from averaging procedure, and presents a measure of the dispersion of measurement values around arithmetic mean [21]. Assessment of type B uncertainty results from familiarity with measuring instruments used in the experiment. This is why it is most often estimated on the basis of the accuracy of the measuring instruments used (information from the manufacturer or past familiarity with the instrument). A great deal of knowledge and experience is required from the experimenter when accepting or assuming the distribution of probability density function for the obtained measurement results when making the assessment. Whereby, expanded uncertainty is normally given as estimated measurement uncertainty, requiring the calculated type A and B uncertainties to be first geometrically put together, and then multiplied by coverage factor $k_{p}$ [19].

The purpose of the conducted fluid flow studies described in this article is to analyze the metrological properties of the selected multi-opening orifice with substitute constriction factor of $\beta=0.5(m=0.25)$ and to determine discharge coefficient $C$. Moreover, an attempt has been made to estimate the relative expanded uncertainty of determining the ratio in a progressing turbulent flow for Reynolds numbers from the range of $R e=4700-19,500$ in laboratory conditions. The available subject literature often lacks such estimation for multi-opening orifices (non-standard orifices) which are more often used after custom calibration in industrial technological processes (conditioning orifice) due to their metrological advantages. The presented analyses and test results complement this knowledge.

\section{The Subject of Study and Measurement Result}

The study was conducted in laboratory conditions in the Fluid Mechanics Laboratory in Faculty of Technology at The President Stanisław Wojciechowski Academy in Kalisz.

For these experimental studies, a four-opening orifice was designed, taking into consideration all the recommendations used when designing a centrical orifice $[5,6]$. The orifice with this design was made of brass. Figure 1 shows a picture and production drawing of the orifice.

The orifice was placed in housing to allow the measurement of the build-up pressure (the measurement of the difference in pressure before and behind the orifice) nearby. The orifice was mounted in the housing in a standard orientation, where the inflow was directed at the sharp edges of flow openings, and the pressure measurement pulse openings were located on an axis between them.

The water testing station was built with two straight and smooth pipeline segments-DN50 and DN15, connected with a bend forming a $180^{\circ}$ angle so that the pipelines would be parallel. The test orifice (Figure 1) was installed in the DN50 straight pipeline with a total length of 82.D. To shape the inlet speed profile, the straight segment before the orifice was $46 \cdot D(2.3 \mathrm{~m})$ long, and $36 \cdot D(1.8 \mathrm{~m})$ long behind the orifice. An Endress + Hauser electromagnetic flowmeter was installed in the DN15 straight pipeline, according to the manual. It functions as the standard/model flow meter in the measuring system where straight segments were taken: $100 \cdot D$ before the flow meter and 50.D behind it. Figure 2 presents the diagram of the water hydraulic flow system.

The water stream produced by the centrifugal pump (1) flows through the vent (2) built into the hydraulic system. When designing it, the continuous flow condition was used, by which it appears that 
within a large cross-section of the vent (DN 150), the average flow velocity inside decreases. It has been made in the form of a vertical sealed cylindrical tank, in which any air bubbles spontaneously separate from the flowing stream generated by the stream pump. Since air may also build up near the upper cover, an additional outlet was installed (side bleeder) which also allows for bleeding adjustment of water stream in the measurement system. Air bubbles saturated from the stream are carried away with the bleeding stream through replaceable choking glands (3), which allow for discrete adjustment of stream in the hydraulic measurement pipeline (4).

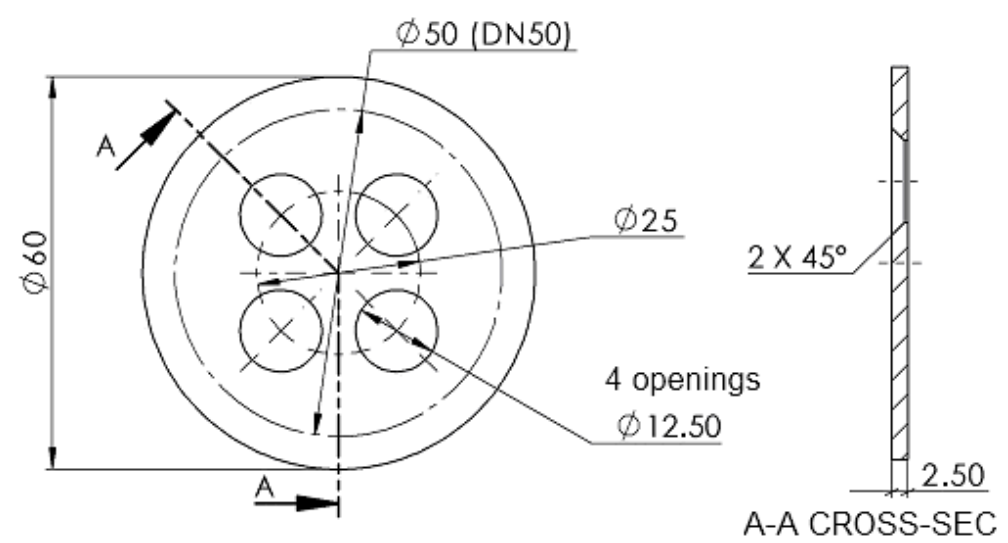

(a)

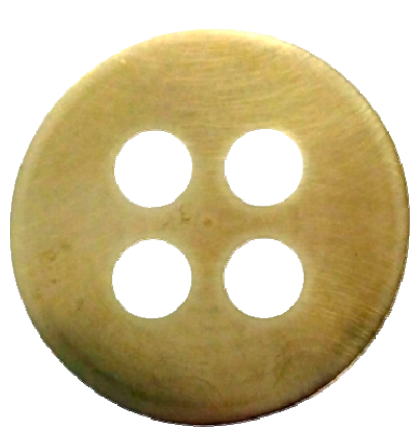

(b)

Figure 1. Multi-opening orifice model: (a) production drawing; (b) brass orifice.

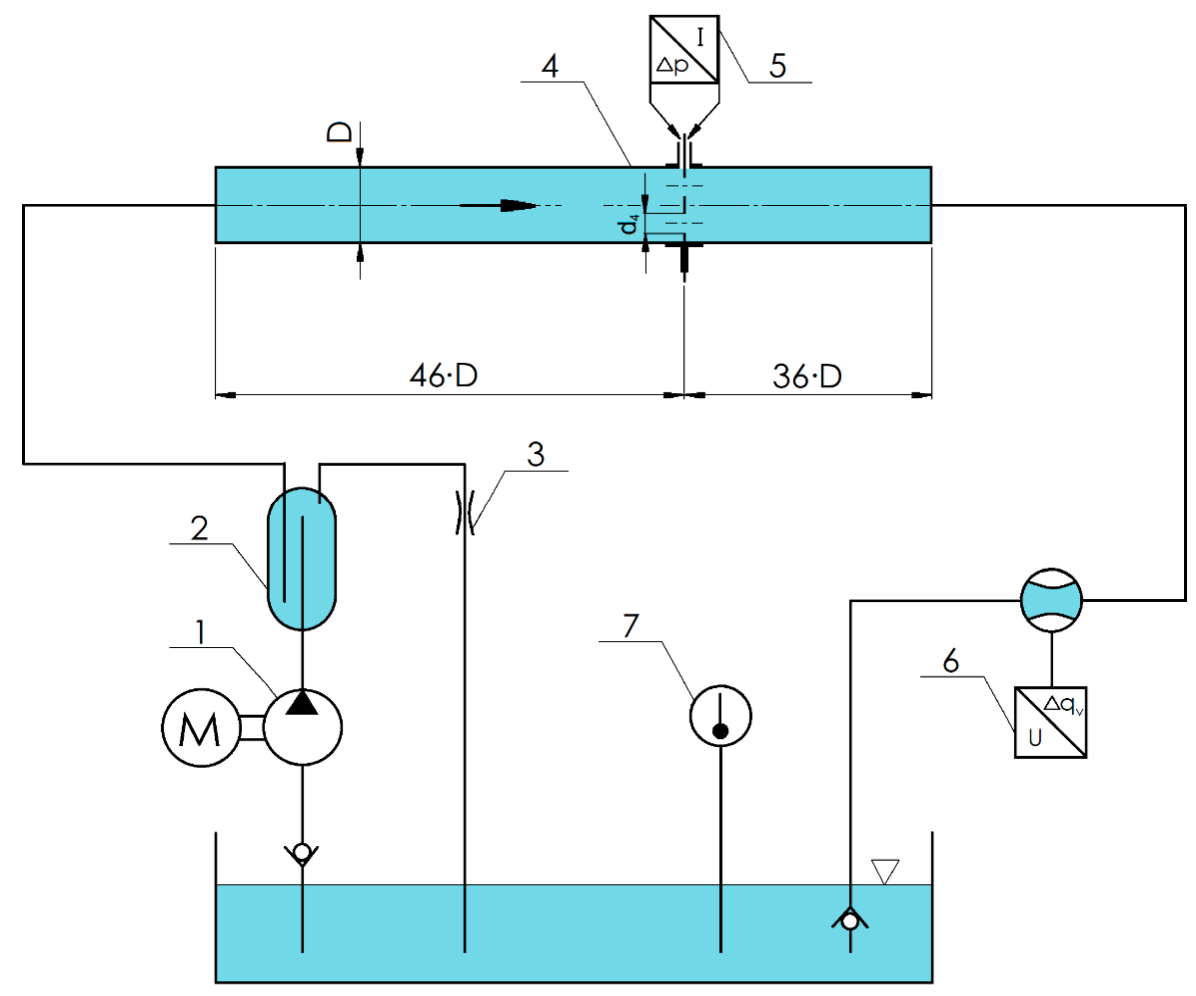

Figure 2. Block scheme of the hydraulic testing station.

In the measurement system (4), the diameter of the pipeline $D$ and the flow-through openings $d_{4}$ in the orifice were measured using a slide caliper with digital display (with resolving power at $0.01 \mathrm{~mm}$ ) for which the limiting error is $0.05 \mathrm{~mm}$. Differential pressure on the tested orifice was measured in close proximity with an APR-2000/ALW (APLISENS SA, Warsaw, Morelowa 7, Poland) differential 
pressure transducer (5). It was programmed for pressure difference measuring range of $\Delta p=0-2.4 \mathrm{kPa}$ with a measuring error of $0.15 \%$ and time constant $t=5 \mathrm{~s}$ with an output current signal of $4-20 \mathrm{~mA}$.

The water stream in the system also flows through the PROMAG 30AT15 magnetic flow meter (6) (used as standard/model in the measuring system). It was set for stream volume in the measuring range of $q_{v}=0-1.0 \mathrm{dm}^{3} / \mathrm{s}$ with measuring error at $\Delta_{q v}= \pm\left(0.2 \% \cdot q_{v-\text { measured }} \pm 0.05 \% \cdot q_{v}\right)$ with time constant $t=5 \mathrm{~s}$ and an output current signal of $0-20 \mathrm{~mA}$.

In the presented measuring system, both the volume stream and water temperature were measured simultaneously for each measurement series, the latter measured with a $0.35 \mathrm{~m}^{3}$ tank thermometer (7). Flow parameters (signals from the flow meter and the differential pressure transducer) were recorded using SANWA 5000 multimeters connected to a measuring system on a PC, using the RS-232 interface. The computer used specialized PC Link Plus software which allowed acquiring measurement data with a preset sampling time at $\Delta t=6 \mathrm{~s}$. A total of 12 volume streams were tested on the described station, with streams $q_{v}$ ranging $0.167-0.683 \mathrm{dm}^{3} / \mathrm{s}$ (for Reynolds numbers ranging $R e=4700-19,500)$. The measurements were taken for a stabilized stream of flowing water, recording 12 series of observations each, and each of the recorded series was averaged from 20 single measurements.

The acquisition of measurement data involved recording the following parameters: volume stream $q_{v}$, pressure difference at the orifice $\Delta p$, and water temperature $T$. For all measurement series, the water temperature did not exceed $1.5^{\circ} \mathrm{C}$ during the study. Table 1 presents the geometry of pipeline $D$, the geometry of orifice flow-through openings $d_{4}$, averaged results of experimental measurements $\left(T, q_{v}, \Delta p\right)$, and corresponding values from calculations: the value of Reynolds numbers $R e$ and discharge coefficient $C$.

Table 1. Results of experimental measurements.

\begin{tabular}{ccccccc}
\hline $\boldsymbol{D}$ & $\boldsymbol{d}$ & $\boldsymbol{T}$ & $\boldsymbol{q}_{\boldsymbol{v}}$ & $\boldsymbol{\Delta} \boldsymbol{p}$ & $\boldsymbol{R} \boldsymbol{C}$ & $\boldsymbol{C}$ \\
\hline $\mathbf{( m m})$ & $\mathbf{( m m )}$ & $\left({ }^{\circ} \mathbf{C}\right)$ & $\mathbf{( \mathbf { d m } ^ { 3 } / \mathbf { s } )}$ & $\mathbf{( P a )}$ & $\mathbf{( - )}$ & $\mathbf{( - )}$ \\
\hline 50.20 & 12.54 & 25.30 & 0.6825 & 2289.4 & 19,479 & 0.6283 \\
\hline 50.26 & 12.53 & 25.40 & 0.6536 & 2098.9 & 18,696 & 0.6284 \\
\hline 50.37 & 12.53 & 25.40 & 0.6202 & 1891.1 & 17,740 & 0.6282 \\
\hline 50.28 & 12.52 & 25.35 & 0.5907 & 1715.4 & 16,879 & 0.6283 \\
\hline 50.31 & 12.52 & 25.25 & 0.5580 & 1533.0 & 15,909 & 0.6278 \\
\hline 50.36 & 12.51 & 25.20 & 0.5196 & 1327.5 & 14,798 & 0.6283 \\
\hline 50.26 & 12.51 & 25.10 & 0.4858 & 1160.2 & 13,802 & 0.6283 \\
\hline 50.25 & 12.52 & 25.00 & 0.4590 & 1035.0 & 13,012 & 0.6285 \\
\hline 50.40 & 12.51 & 24.95 & 0.4145 & 843.1 & 11,739 & 0.6289 \\
\hline 50.22 & 12.53 & 24.90 & 0.3456 & 581.9 & 9774 & 0.6310 \\
\hline 50.35 & 12.52 & 24.85 & 0.2537 & 310.4 & 7168 & 0.6344 \\
\hline 50.24 & 12.52 & 24.75 & 0.1666 & 130.0 & 4697 & 0.6439 \\
\hline
\end{tabular}

Based on the results of experimental measurements (Table 1), a flow characteristics chart was made for the tested multi-opening orifice with module $m=0.25$ (see Figure 3). The characteristics are described with a power equation with the coefficient of determination close to 1 , which indicates a very good adjustment of the designated model (trend line) to the averaged results obtained from the experiment. 


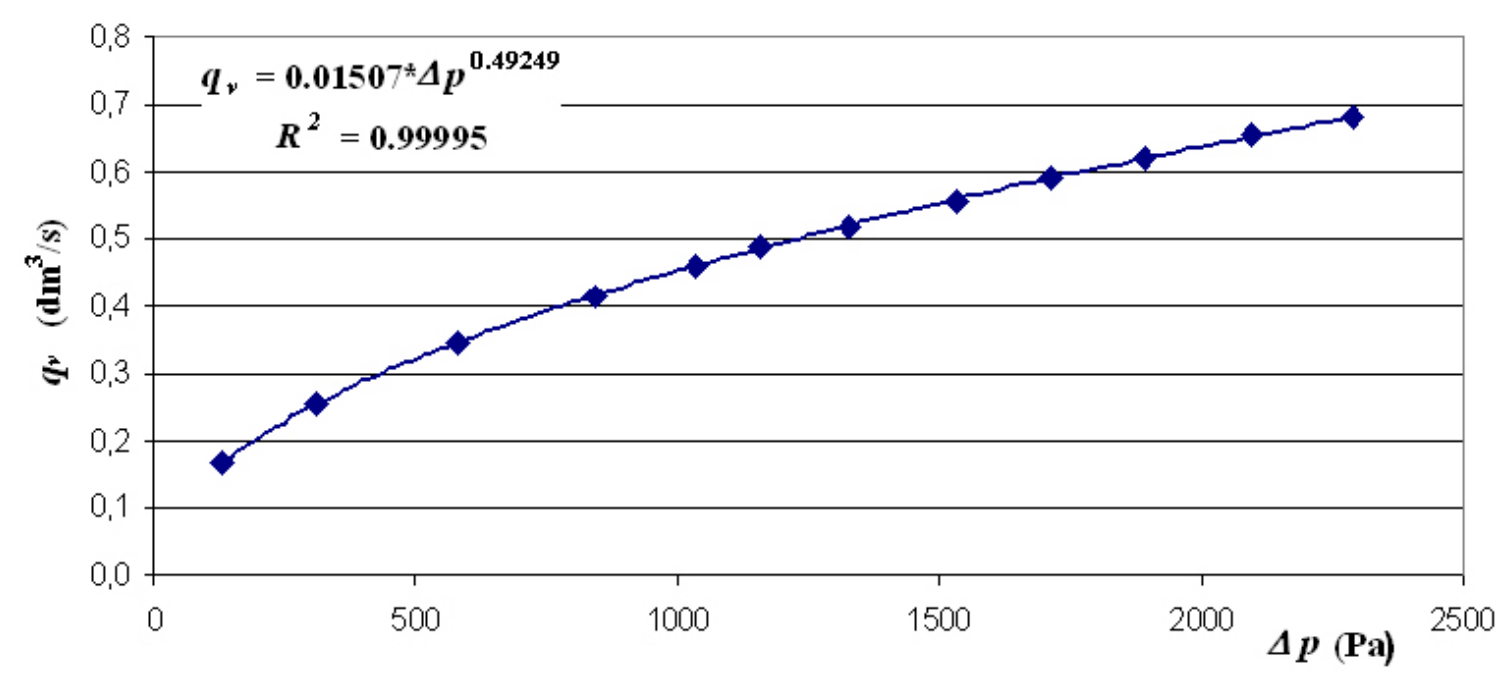

Figure 3. Flow characteristics of the tested orifice $q_{v}=\mathrm{f}(\Delta p)$.

\section{Determining the Uncertainty of the Discharge Coefficient}

This chapter presents the results of the conducted analysis for determining the uncertainty $[12,13]$ of discharge coefficient $C$ through the tested multi-opening orifice. Fluid volume stream $q_{v}$ flowing through the tested multi-opening orifice can be described with a known dependence (1) [5] as

$$
q_{v}=\frac{C \cdot \varepsilon \cdot F_{04}}{\sqrt{1-m^{2}}} \cdot \sqrt{\frac{2 \cdot \Delta p}{\rho}}
$$

The orifice constriction cross-section area is composed of four identical openings with diameter $d_{4}$ (Figure 1), and is presented with a dependence (2):

$$
F_{04}=\frac{4 \cdot \pi \cdot d_{4}^{2}}{4}=\pi \cdot d_{4}^{2}
$$

It was assumed that the ratio of constriction from the cross-section area $F_{04}$ to the pipeline cross-section $F_{D}$ is module $m$ of the orifice. In further deliberations, an individual constriction of a single opening of the four-opening orifice was introduced as $\beta_{4}=d_{4} / D$ (the following diameters were considered in flow cross-sections: diameter of pipeline $D$ and $d_{4}$ as one of four identical openings in the multi-opening orifice). The result was a dependence (3):

$$
m=\frac{F_{04}}{F_{D}}=\frac{4 \cdot d_{4}^{2}}{D^{2}}=4 \cdot \beta_{4}^{2}
$$

Assuming incompressibility of flowing water $(\varepsilon=1)$ for experimental studies, and considering dependence (2) and (3) in Formula (1), an expression for volume stream was obtained (4):

$$
q_{v}=C \cdot \pi \cdot \frac{d_{4}^{2}}{\sqrt{1-16 \cdot \beta_{4}^{4}}} \cdot \sqrt{\frac{2 \cdot \Delta p}{\rho}}
$$

By transforming the designated dependence (4), formula for discharge coefficient $C$ was determined in the following form (5):

$$
C=\frac{q_{v} \cdot \sqrt{1-16 \cdot \beta_{4}^{4}}}{\pi \cdot d_{4}^{2} \cdot \sqrt{\frac{2 \cdot \Delta p}{\rho}}}
$$


For the discharge coefficient defined in (5), the standard relative uncertainty of its determination $u(C) / C$ was calculated. It was determined from measurements of the values, indirectly according to the propagation of uncertainty rule [12] from Formula (6):

$$
\begin{gathered}
\frac{u(C)}{C}=\left[\left(\frac{1}{C} \cdot \frac{\partial C}{\partial q_{v}} \cdot u\left(q_{v}\right)\right)^{2}+\left(\frac{1}{C} \cdot \frac{\partial C}{\partial \Delta p} \cdot u(\Delta p)\right)^{2}+\left(\frac{1}{C} \cdot \frac{\partial C}{\partial \rho} \cdot u(\rho)\right)^{2}+\right. \\
\left.+\left(\frac{1}{C} \cdot \frac{\partial C}{\partial d_{4}} \cdot u\left(d_{4}\right)\right)^{2}+\left(\frac{1}{C} \cdot \frac{\partial C}{\partial D} \cdot u(D)\right)^{2}\right]^{0.5}
\end{gathered}
$$

Next, based on dependence (6), partial derivatives were determined. When multiplied by the converse discharge coefficient (5), they yield components of Equation (6). They are presented in Table 2.

Table 2. Components determined from Equation (6).

\begin{tabular}{cc}
\hline Partial Derivatives & Equation (6) Components \\
\hline$\frac{\partial C}{\partial q_{v}}=\frac{\sqrt{1-16 \cdot \beta_{4}^{4}}}{\pi \cdot d_{4}^{2} \cdot \sqrt{\frac{2 \cdot \Delta p}{\rho}}}$ & $\frac{1}{C} \cdot \frac{\partial C}{\partial q_{v}}=\frac{1}{q_{v}}$ \\
\hline$\frac{\partial C}{\partial \Delta p}=\frac{q_{v} \cdot \sqrt{1-16 \cdot \beta_{4}^{4}}}{\pi \cdot d_{4}^{2} \cdot \sqrt{\frac{2 \cdot \Delta p}{\rho}} \cdot \frac{(-1)}{2 \cdot \Delta p}}$ & $\frac{1}{C} \cdot \frac{\partial C}{\partial \Delta p}=-\frac{1}{2} \cdot \frac{1}{\Delta p}$ \\
\hline$\frac{\partial C}{\partial \rho}=\frac{q_{v} \cdot \sqrt{1-16 \cdot \beta_{4}^{4}}}{\pi \cdot d_{4}^{2} \cdot \sqrt{\frac{2 \cdot \Delta p}{\rho}} \cdot \frac{1}{2 \cdot \rho}}$ & $\frac{1}{C} \cdot \frac{\partial C}{\partial \rho}=\frac{1}{2} \cdot \frac{1}{\rho}$ \\
\hline$\frac{\partial C}{\partial d_{4}}=\frac{q_{v}}{\pi \cdot \sqrt{\frac{2 \cdot \Delta p}{\rho}} \cdot\left(\frac{-2}{d_{4}^{3} \cdot \sqrt{1-16 \cdot \beta_{4}^{4}}}\right)}$ & $\frac{1}{C} \cdot \frac{\partial C}{\partial d_{4}}=-\frac{2}{1-16 \cdot \beta_{4}^{4}} \cdot \frac{1}{d_{4}}$ \\
\hline$\frac{\partial C}{\partial D}=\frac{q_{v}}{\pi \cdot \sqrt{\frac{2 \cdot \Delta p}{\rho}} \cdot \frac{32 \cdot \beta_{4}^{2}}{D^{3} \cdot \sqrt{1-16 \cdot \beta_{4}^{4}}}}$ & $\frac{1}{C} \cdot \frac{\partial C}{\partial D}=\frac{32 \cdot \beta_{4}^{4}}{1-16 \cdot \beta_{4}^{4}} \cdot \frac{1}{D}$ \\
\hline
\end{tabular}

After substituting components of Equations (7)-(11) in Equation (6) for combined relative standard uncertainty of determining discharge coefficient $u(C) / C$, the dependence (12) was obtained:

$$
\begin{gathered}
\frac{u(C)}{C}=\left[\left(\frac{u\left(q_{v}\right)}{q_{v}}\right)^{2}+\frac{1}{4} \cdot\left(\frac{u(\Delta p)}{\Delta p}\right)^{2}+\frac{1}{4} \cdot\left(\frac{u(\rho)}{\rho}\right)^{2}+\left(\frac{2}{1-16 \cdot \beta_{4}^{4}}\right)^{2} \cdot\left(\frac{u\left(d_{4}\right)}{d_{4}}\right)^{2}+\right. \\
\left.+\left(\frac{32 \cdot \beta_{4}^{4}}{1-16 \cdot \beta_{4}^{4}}\right)^{2} \cdot\left(\frac{u(D)}{D}\right)^{2}\right]^{0.5}
\end{gathered}
$$

\begin{tabular}{|c|c|}
\hline$\frac{u\left(q_{v}\right)}{q_{v}}=\frac{\sqrt{S_{\left(q_{v}\right)}^{2}+\left(\frac{\Delta_{\left(q_{v}\right)}}{\sqrt{3}}\right)^{2}}}{q_{v}} \cdot 100 \%$ & (13) \\
\hline$\frac{u(\Delta p)}{\Delta p}=\frac{\sqrt{S_{(\Delta p)}^{2}+\left(\frac{\Delta_{(\Delta p)}}{\sqrt{3}}\right)^{2}}}{\Delta p} \cdot 100 \%$ & (14) \\
\hline$\frac{u(\rho)}{\rho}=\frac{\frac{\Delta(\rho)}{\sqrt{3}}}{\rho} \cdot 100 \%$ & (15) \\
\hline$\frac{u\left(d_{4}\right)}{d_{4}}=\frac{\sqrt{S_{\left(d_{4}\right)}^{2}+\left(\frac{\Delta_{\left(d_{4}\right)}}{\sqrt{3}}\right)^{2}}}{d_{4}} \cdot 100 \%$ & (16) \\
\hline$\frac{u(D)}{D}=\frac{\sqrt{S_{(D)}^{2}+\left(\frac{\Delta_{(D)}}{\sqrt{3}}\right)^{2}}}{D} \cdot 100 \%$ & (17) \\
\hline
\end{tabular}

Table 3 presents relative standard components of uncertainty, present in Equation (12), necessary for calculating the combined relative standard uncertainty of discharge coefficient $u(C) / C$.

Table 3. Relative standard components of the uncertainty of Equation (12). 
Experimental standard deviations $S$ in Formulas (13)-(17) represent type A random uncertainties of average measured values. With 12 observations conducted, the deviations were increased by Student's distribution critical factor $\left(k_{n}=2.2\right)$ with assumed confidence level $p=0.95$. To determine type B uncertainty, a rectangular distribution of probability was assumed, where the $\Delta$ symbol marked absolute maximum limiting errors of input value data measurements, resulting from the use of the measuring instruments. Eventually, following the EN ISO 5167-1 standard [5] and dependence (12), we can determine the relative expanded uncertainty of discharge coefficient $U(C) / C$ (for confidence level $p=95 \%$ with coverage factor $k_{p}=2$ ) for the multi-opening orifice and present it in the form of Formula (18):

$$
\frac{U(C)}{C}=k_{p} \cdot \frac{u(C)}{C}
$$

\section{Results and Discussion}

This article has presented the results of experimental studies of a multi-opening orifice with substitute constriction factor $\beta=0.5$, mounted in a DN50 hydraulic measuring channel. Based on the obtained averaged results from experiments, flow characteristics were determined and described with a simplified power equation with an exponent close to 0.5 , and with the determination coefficient close to 1 , which indicates a very good adjustment of the designated model (trend line) to the averaged results obtained from the experiment. Based on calculations from averaged measurement data, the value of discharge coefficient $C$ was determined in a progressing turbulent flow for low Reynolds numbers $(R e=4700-19,500)$ in laboratory conditions.

Figure 4 presents values of relative expanded uncertainty of discharge coefficient $U(C) / C$ based on experimental studies, in the form of dots, for the multi-opening orifice (Figure 1) within the range of volume stream change $q_{v}=0.167-0.683 \mathrm{dm}^{3} / \mathrm{s}$.

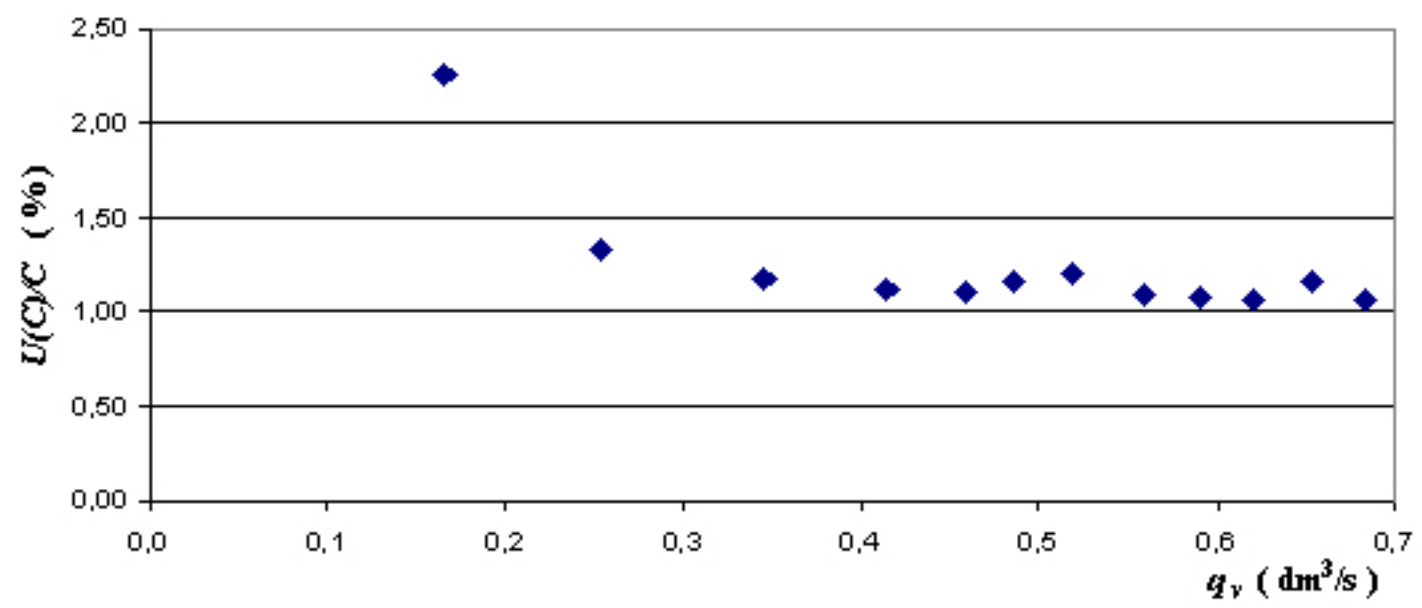

Figure 4. Distribution of relative expanded uncertainty of flow ratio $U(C) / C$ dependent upon volume stream $q_{v}$.

When analyzing the presented graph, we may state that the relative expanded uncertainty of determining discharge coefficient $U(C) / C$ does not exceed $1.25 \%$ for volume stream $q_{v} \geq 0.35 \mathrm{dm}^{3} / \mathrm{s}$ in the studied measurement range. On the other hand, Figure 5 presents values of discharge coefficient $C$, determined based on the conducted experimental studies, in the function of Reynolds numbers $(R e=4700-19,500)$ with bars representing errors that result from calculating its expanded uncertainty $U(C)$ with coverage factor $k_{p}=2$ and confidence level $p=0.95$.

When analyzing the graph in Figure 5, we can assume that, for Reynolds numbers ranging $9800 \leq$ $R e \leq 19,500$, the values of the discharge coefficient are close to a straight line, and the values only change a little. This allows us to assume the constant average value of discharge coefficient at $C=0.6286$ and bars representing errors of determining its absolute expanded uncertainty do not exceed \pm 0.0076 . 


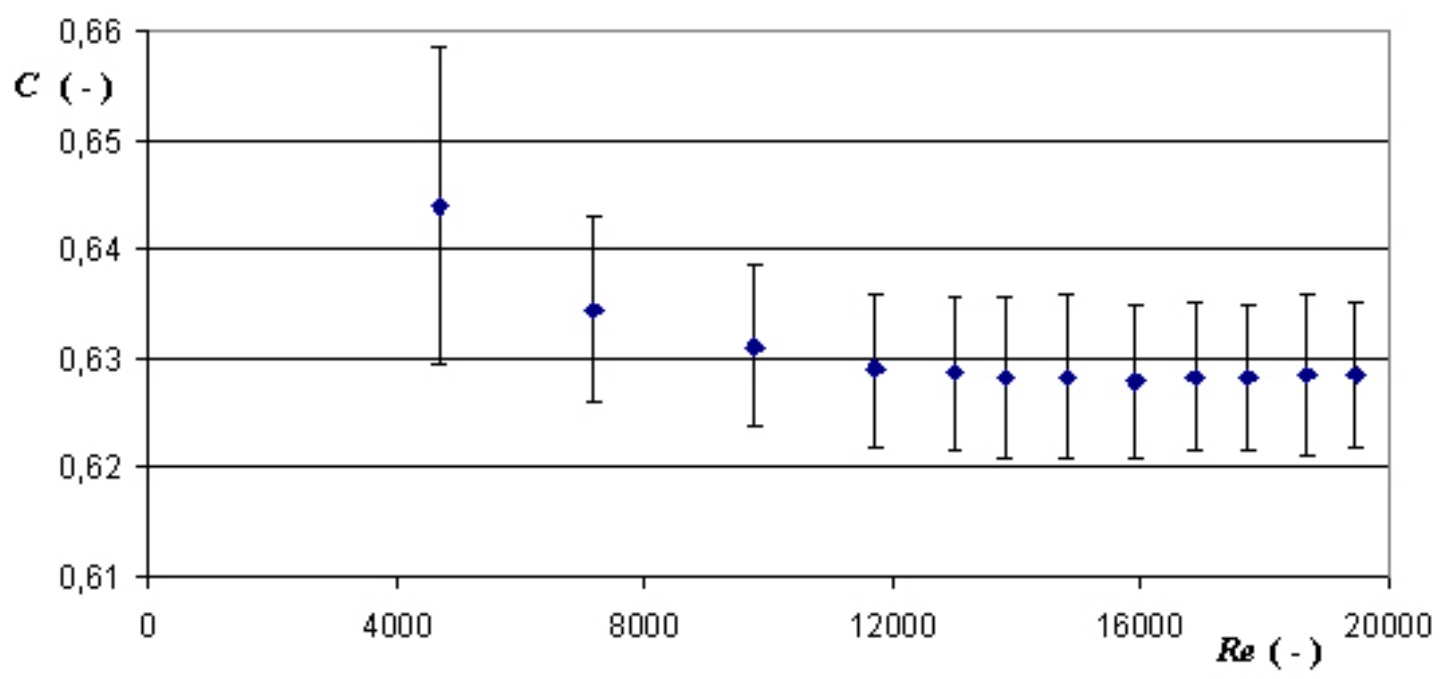

Figure 5. Value of discharge coefficient $C$ depending on Reynolds number $R e$.

\section{Conclusions}

The presented study results for a multi-opening orifice (Figure 1), with pressure measured in close proximity, indicate that in the tested range for $R e \geq 9800$ numbers, we can observe the following:

- There is the constancy of discharge coefficient (its average value $C=0.6286$ ) which is higher than the discharge coefficient for a centrical orifice by ca. $2.0 \%$ with the same constriction;

- Relative expanded uncertainty of determining discharge coefficient $U(C) / C$ does not exceed $1.25 \%$ and is close in value to standardized orifices.

Further experimental studies are planned for a highly progressed turbulent flow $(\operatorname{Re}>20,000)$ including, among others, the influence of speed profile perturbation on the metrological properties of a multi-opening orifice.

Funding: This research received no external funding.

Conflicts of Interest: The authors declare no conflict of interest.

\section{Abbreviations}

C discharge coefficient

D measurement pipeline diameter $(\mathrm{m})$

$d_{4} \quad$ orifice openings diameter $(\mathrm{m})$

$F_{04} \quad$ orifice constriction area $\left(\mathrm{m}^{2}\right)$

$k_{n} \quad$ Student's distributoon critical factor

$k_{p} \quad$ coverage factor

$m \quad$ orifice module

$q_{v} \quad$ volume stream $\left(\mathrm{m}^{3} / \mathrm{s}\right)$

Re Reynolds number

$S \quad$ standard deviation of the measured values

$T \quad$ fluid (water) temperature $\left({ }^{\circ} \mathrm{C}\right)$

$u(C) \quad$ standard uncertainty of the measured estimation, $C$

$U(C) / C \quad$ relative expanded uncertainty of discharge coefficient

$u(D) \quad$ standard uncertainty of the measured estimation, $D$

$u\left(d_{4}\right) \quad$ standard uncertainty of the measured estimation, $d_{4}$

$u\left(q_{v}\right) \quad$ standard uncertainty of the measured estimation, $q_{v}$

$u(\ddot{\mathrm{A}} p) \quad$ standard uncertainty of the measured estimation, $\ddot{\mathrm{A}} p$

$u(\hat{n}) \quad$ standard uncertainty of the measured estimation, $\dot{n}$ 
$\hat{a} \quad$ substitute constriction factor

$\hat{a}_{4} \quad$ constriction of one of the four orifice openings $\left(\hat{a}_{4}=d_{4} / D\right)$

$\ddot{A} \quad$ maximum limiting errors of measuring instruments used

$\ddot{A} p \quad$ pressure difference before and behind the orifice $(\mathrm{Pa})$

i expansion factor

n. fluid density $\left(\mathrm{kg} / \mathrm{m}^{3}\right)$

\section{References}

1. Zhang, R.; Hang, Y. An Experimental Study of Pulsatile Flow in a Compliant Aortic Root Model dunder Varied Cardiac Outputs. Fluids 2018, 3, 71. [CrossRef]

2. Gondek, A. Przeptywomierze Spiętrzajace Przeptyw (Flow Meters that Bank up the Flow); Politechnika Krakowska: Kraków, Poland, 2009. (In Polish)

3. Kremlowski, P.P. Raschodimiery i Scetciki Kolicestva, Vescestv; Izd. Politechnika: Saint Petersburg, Russia, 2002.

4. Turkowski, M. Metrologia Przeptywów (Flow Metrology); Oficyna Wydawnicza Politechniki Warszawskiej: Warszawa, Poland, 2018. (In Polish)

5. International Organization for Standardization. EN ISO 5167-1: 2003 Measurement of Fluid Flow by Means of Pressure Differential Devices Inserted in Circular Cross-Section Conduits Running Full_Part 1: General Principles and Requirements; ISO: Geneva, Switzerland, 2003.

6. International Organization for Standardization. EN ISO 5167-2: 2003 Measurement of Fluid Flow by Means of Pressure Differential Devices Inserted in Circular Cross-Section Conduits Running Full_Part 2: Orifice Plates; ISO: Geneva, Switzerland, 2003.

7. Golijanek-Jędrzejczyk, A.; Mrowiec, A.; Hanus, R.; Zych, M.; Świsulski, D. Uncertainty of mass flow measurement using centric and eccentric orifice for Reynolds number in the range 10,000 $\leq \operatorname{Re} \leq 20,000$. Measurement 2020, 160, 107851. [CrossRef]

8. Tomaszewska-Wach, B.; Rząsa, M.R.; Majer, M. Measurement of two-phase gas-liquid flow using standard and slotted orifice. Inf. Autom. Pomiary Gospod. Ochr. Śr. 2019, 9, 30-33. [CrossRef]

9. Dhumal, D.S.; More, Y.R.; Gawai, U.S. Design, Fabrication \& Analysis of Multi-Hole Orifice Plate. Int. J. Eng. Technol. 2017, 6, 353-357.

10. Huang, S.; Ma, T.; Wang, D.; Lin, Z. Study on discharge coefficient of perforated orifices as a new kind of flowmeter. Exp. Therm. Fluid Sci. 2013, 46, 74-83. [CrossRef]

11. Romanik, G.; Rogula, J. The novel solution of ball valve witch replaceable orifice. Numericl and field tests. Open Eng. 2019, 9, 253-259. [CrossRef]

12. Mahendra Babu, K.J.; Gangadhara Gowda, C.J.; Ranjith, K. Numerical Study on Performance Characteristics of Multihole Oriface Plate. IOP Conf. Ser. Mater. Sci. Eng. 2018, 376. [CrossRef]

13. Durdewic, M.; Bukurov, M.; Tasin, S.; Bikic, S. Experimental research of single-hole and multi-hole orifice gas flow meters. Flow Meas. Instrum. 2019, 70, 101615. [CrossRef]

14. Bagade, V.S.; Suryawanshi, P.M.; Nalavade, S.M. A review of multi-hole orifice plate. Int. J. Res. Appl. Sci. Eng. Technol. 2019, 7, 3197-3208. [CrossRef]

15. Hao, C.Z.; Song, X.M.; Jia, Z.N. Influence of the hole chamfer on the characteristics of a multi-hole orifice flowmeter. Fluid Dyn. Mater. Process. 2019, 15, 391-401. [CrossRef]

16. Singh, V.K.; Tharakan, T.J. Numerical simulations for multi-hole orifice flow meter. Flow Meas. Instrum. 2015, 45, 375-383. [CrossRef]

17. Drikakis, D.; Asproulis, N. Quantification of Computational Uncertainty in Science and Engineering. ASME Appl. Mech. Rev. 2011, 64. [CrossRef]

18. Barmparousis, C.; Drikakis, D. Multidimensional quantification of uncertainty and application to a turbulent mixing model. Int. J. Numer. Meth. Fluids 2017, 85, 385-403. [CrossRef]

19. Guide to the Expression of Uncertainty in Measurement, Joint Committee for Guides in Metrology (JCGM) 100:2008. Available online: https://www.bipm.org/utils/common/documents/jcgm/JCGM_100_2008_E.pdf (accessed on 16 October 2020).

20. Diaz, R.P.; Dalfre Filho, J.G.; de Lucca, Y.F.L. Water flow meter measurement uncertainties. Water Resour. Manag. 2013, 171. [CrossRef] 
21. Wiora, J.; Wiora, A. Measurement Uncertainty Calculations for $\mathrm{pH}$ Value Obtained by an Ion-Selective Electrode. Sensors 2018, 18, 1915. [CrossRef] [PubMed]

Publisher's Note: MDPI stays neutral with regard to jurisdictional claims in published maps and institutional affiliations.

(C) 2020 by the author. Licensee MDPI, Basel, Switzerland. This article is an open access article distributed under the terms and conditions of the Creative Commons Attribution (CC BY) license (http://creativecommons.org/licenses/by/4.0/). 